\title{
Brown Root Rot of 10 Species of Fruit Trees Caused by Phellinus noxius in Taiwan
}

\author{
P. J. Ann, Department of Plant Pathology, Taiwan Agricultural Research Institute, Wufeng, Taichung, Taiwan; and \\ H. L. Lee and T. C. Huang, Taitung District Agricultural Improvement Station, Taitung, Taiwan
}

\begin{abstract}
Ann, P. J., Lee, H. L., and Huang, T. C. 1999. Brown root rot of 10 species of fruit trees caused by Phellinus noxius in Taiwan. Plant Dis. 83:746-750.

Wilt and death of fruit trees was surveyed from 1990 to 1996. Most trees with decline symptoms in central and southern Taiwan had brown root rot caused by Phellinus noxius. The infected trees included litchi, sugar-apple, plumum, pear, loquat, persimmon, carambola, wax apple, grape, and jellyfig, with ages ranging from young seedlings up to 10 -year-old trees. Symptoms were leaf discoloration, unthrifty appearance, and eventual death. Upon inoculation of the roots with $P$. noxius grown in a wheat-oat medium, healthy seedlings of these 10 tree species were killed. $P$. noxius was reisolated from diseased tissues of inoculated roots. The isolates of $P$. noxius obtained from different hosts were similar in morphological characteristics. Host specificity among the tested isolates was not observed in the cross-inoculation test, but variability in virulence was noted in some tests. Mycelial growth of different isolates of $P$. noxius showed similar temperature response, but the growth rates varied dramatically. Fruiting bodies were rarely found in the field. However, the fungus produced fruiting bodies artificially, on a sawdust medium, that were similar to those produced on the lower stems of declining trees. Brown root rot can be induced by replanting seedlings in infested soil or by contact with the diseased or dead roots. P. noxius causing brown root rot of these 10 fruit trees has not been previously reported.
\end{abstract}

In the last 10 years, decline and wilt of longan (Dimocarpus longana $=$ Euphorbia longana), litchi (Litchi chinensis), sugarapple (Annona squamosa), plumum (Prunus mume), pear (Pyrus pyrifolia var. culata, $P$. pyrifolia var. yokoyama), loquat (Eriobotrya japonica), persimmon (Diospyros kaki), and some other important fruit trees has been frequently noticed in the central and southern counties of Taiwan. Affected trees showed slow growth, discoloration of leaves and defoliation, wilt, and eventual death of the whole plants within 3 to 5 years. Occasionally the whole canopy appeared chlorotic, and the affected plants died within a few months. The root bark of the diseased plants appeared rough and was covered with a thick layer of fungal mycelial mat and soil particles. The decline of longan trees in Taiwan has recently been proven to be caused by Phellinus noxius (Corner) G.H. Cunningham (1). The fungus is distributed worldwide in the tropics and subtropics and causes serious root rot of many woody

Corresponding author: P. J. Ann

E-mail: pjann@wufeng.tari.gov.tw

Contribution 1965 of Taiwan Agricultural Research Institute.

Accepted for publication 15 April 1999.

Publication no. D-1999-0607-02R

(C) 1999 The American Phytopathological Society plants $(2,4,5,10)$. Currently, it has become a serious problem for many types of fruit tree plantations in Taiwan. Our objectives were to isolate the causal fungus and to explain its relation to the decline of 10 important fruit tree species.

\section{MATERIALS AND METHODS}

Isolation, cultivation, and maintenance. Diseased root tissues were taken from declining fruit trees. Pieces (approx. $5 \times 2 \times 1 \mathrm{~mm}$ ) of infected tissues, cut from the advancing margins, were surface-sterilized with $0.5 \% \mathrm{NaClO}$ for $3 \mathrm{~min}$, placed on potato dextrose agar (PDA) in petri dishes, and incubated at $24^{\circ} \mathrm{C}$. To avoid contamination with bacteria and other soil fungi, PDA was amended with ampicillin (100 ppm) and benomyl (10 ppm) after autoclaving. The fungus growing from the diseased tissues was transferred to $2 \%$ water agar for single hyphal tip isolation. Single hyphal tip isolates were cultured on PDA for further studies. For maintenance, 5- to 10-day-old cultures, each grown on PDA, were cut into pieces (approx. $10 \times 5$ $\times 3 \mathrm{~mm}$ ), transferred into test tubes containing sterile distilled water, and kept at $20^{\circ} \mathrm{C}$.

Meanwhile, soil was collected from the rhizosphere of each diseased orchard. In each orchard, soil was taken from five points and mixed. The $\mathrm{pH}$ was determined with a $\mathrm{pH}$ meter after the soil was mixed with distilled water $(1: 1, \mathrm{wt} / \mathrm{vol})$ for 30 min. The $\mathrm{pH}$ values of soil from healthy orchards were also measured for comparison.

Pathogenicity tests. The fungus was grown in a wheat-oat medium (25 $\mathrm{g}$ of whole wheat grains, $25 \mathrm{~g}$ of whole oat grains, and $25 \mathrm{ml}$ of distilled water in a $500-\mathrm{ml}$ flask) for 1 month at $24^{\circ} \mathrm{C}$ (6). Roots of 2- to 3-year-old seedlings of each fruit tree, individually planted in pots $(25$ $\mathrm{cm}$ diameter), were exposed, surface-sterilized with $70 \%$ alcohol, and scraped gently to remove the epidermis (approx. $2 \mathrm{~cm}$ $\times 5 \mathrm{~mm}$ ). About $5 \mathrm{~g}$ of wheat-oat culture was placed on the scraped portion of the root, wrapped with a sheet of clear plastic, and secured at both ends. Roots similarly inoculated with sterile wheat-oat medium were used as controls. Five seedlings were used for each treatment, and the experiments were repeated once or twice. Data were analyzed by analysis of variance (ANOVA), and means were compared using the least significant difference test (LSD).

Production of fruiting bodies. Sawdust medium (8) consisting of sawdust, rice bran, sucrose, and $\mathrm{CaCO}_{3}$ in plastic bags (approx. $20 \mathrm{ml}$ long, $10 \mathrm{~cm}$ diameter) was used for formation of fruiting bodies. Each plastic bag was inoculated with 5 pieces of inoculum and incubated at $24^{\circ} \mathrm{C}$. After 1 month, the plastic bag was removed and the fungus-colonized medium was placed on moist sand in a greenhouse at room temperature (1).

Identification of the pathogen. Potato dextrose agar was used to study the cultural and morphological characteristics of the fungus. All tested isolates were grown on PDA in petri dishes at $24^{\circ} \mathrm{C}$ under 2,000 $\operatorname{lux}(12 \mathrm{~h} /$ day $)$ for 20 days. Colonial patterns were recorded daily and described. Clamp connections and spore formations were examined microscopically every 3 days. Key of Polyporaceae described by Cunningham in 1965 (4) was used for identification of the isolated fungus.

Growth of fungi. To determine the effect of temperature on growth of the test organisms, agar disks $(5 \mathrm{~mm}$ diameter $)$ were cut with a sterile cork borer from the periphery of colonies and placed on PDA in a growth rate tube $(30 \mathrm{~cm}$ long, $1.5 \mathrm{~cm}$ diameter) (11). Inoculated tubes were incubated at 10,12, 15, 18, 21, 24, 27, 30, 33 , or $36^{\circ} \mathrm{C}$ in darkness. Colonies were measured daily until the fungus reached the end of the tubes or 20 days after inoculation. Three tubes were used for each treatment, and the experiment was done twice. 
To determine the effect of $\mathrm{pH}$ on growth of the test organisms, five agar disks (5 $\mathrm{mm}$ diameter) cut with a sterile cork borer from the periphery of a colony were placed in a $250-\mathrm{ml}$ flask containing $100 \mathrm{ml}$ of potato dextrose broth (PD broth). The $\mathrm{pH}$ value of PD broth in each flask was adjusted to $4.0,4.5,5.0,5.5,6.0,6.5,7.0$, $7.5,8.0,8.5$, or 9.0 , respectively, with $1 \mathrm{~N}$ $\mathrm{HCl}$ or $\mathrm{KOH}$ after autoclaving. The inoculated flasks were incubated at $24^{\circ} \mathrm{C}$ in darkness for 10 days. Mycelial mats were harvested, air-dried for $24 \mathrm{~h}$ at $60^{\circ} \mathrm{C}$, and weighed. Two flasks were used for each treatment, and the experiment was done twice. The experiments were arranged in a completely randomized design. Data were analyzed by ANOVA, and means were compared using the least significant difference test (LSD).

Dissemination tests. Soil from the rhizosphere of the dead longan trees in an orchard in the mountain area in Tainan was sieved by passing it through a screen with a pore size of $2 \mathrm{~mm}$ diameter. Forty 3month-old seedlings of sugar-apple were planted in individual pots, each containing $500 \mathrm{~g}$ of infested soil. Forty seedlings planted in the soils from a healthy orchard were used as controls. Death and wilt of seedlings was recorded monthly. Isolations were made from root tissues of the dead seedlings.

Two- to 3-year-old loquat seedlings grown in pots were inoculated with oatwheat medium colonized with $P$. noxius as described in the procedure for the pathogenicity test. After 6 months, almost all of the inoculated seedlings died. The aboveground portions of the dead seedlings were then cut. Two young seedlings (6 month old) were then planted around each dead root in the same pots. Ten pots containing dead roots were used. Two seedlings were planted in pots containing healthy plant roots (tops of plants removed) as control. Presence of wilt symptoms and mortality were recorded monthly. Isolations were made from root tissues of the dead seedlings.

\section{RESULTS}

Isolations and symptoms. The same fungus was consistently isolated from the diseased roots of 10 species of fruit trees which showed the decline and brown root rot symptoms (Table 1). The diseased plants were found in central, southern, and eastern areas of Taiwan including Maioli, Taichung, Nantow, Yunlin, Chiayi, Tainan, Kaohsiung, and Taitung counties. The $\mathrm{pH}$ of soils collected from the diseased fields ranged from 3.9 to 5.0 (Table 1), whereas healthy soils ranged from 3.8 to 8.0.

The 10 different kinds of infected fruit trees included litchi, sugar-apple, plumum, pear, loquat, persimmon, carambola (Averrhoa carambola), wax apple (Syzygium samarangense), grape (Vitis vinifera), and jellyfig (Ficus pumila var. awkeotsan), which had similar external and internal symptoms of brown root rot. Infected fruit plants ranged from 2 to 50 years old. In most cases, decline of fruit trees occurred in monoculture orchards only. However, three multicropping orchards were also found with the same disease, and all kinds of plants in the orchards were infected. One orchard was planted with longan, loquat, and sugar-apple, the other one contained longan and wax apple, while the third one was a mixture of plumum and bauhinia (unpublished). In the infected orchards, the diseased plants with decline symptoms usually appeared in one or few localized sites in the beginning, and then the disease extended outward slowly year by year. Sometimes, all of the susceptible plants in an untreated infected orchard died gradually.

The disease symptoms were discoloration of leaves followed by gradual defoliation, slow growth, and eventual death of the infected trees. Occasionally the whole canopy, especially in litchi, loquat, and wax apple, turned brown within 2 to 3 months, and the affected trees died sud- denly. Sometimes the decline symptoms on grape and sugar-apple appeared after pruning as a cessation of new budding and growth. Extensive root rot was found on all diseased trees examined. The outer surface of the infected bark appeared rough due to being covered with a thick layer (sometimes up to $5 \mathrm{~mm}$ ) of an adhering mixture of soil particles and brownish fungal mycelial mats. Since jellyfig trees were attached to big stones for growing, thick layers of brown mycelial mats (up to $80 \times$ $80 \times 1 \mathrm{~cm})$ around the diseased stems and roots were formed on the stone surface of the shaded site. Dead infected bark was brittle and could be removed easily. The inner surface of the infected bark was covered with white to brownish mycelial mats with a network of mycelial cords. Infected roots initially turned brown and discolored and then became white and soft with a conspicuous network of brown lines permeating the wood tissues (Fig. 1). The infected woody tissues eventually decomposed and showed typical white rot symptoms. The diseased trees also died when the infection reached the root crown. My-

Table 1. Isolation of Phellinus noxius from root tissues of fruit trees with of decline and brown root rot symptoms

\begin{tabular}{llc}
\hline Host & Location and no. of infected orchards & pH of diseased soil \\
\hline Litchi & Kaohusing (1), Tainan (2), Chiayi (3), Taichung (1) & $3.9-4.9$ \\
Sugar-apple & Taitung (15), Tainan (2), Yunlin (1), Taichung (1) & $4.5-5.03$ \\
Plumum & Kaohusing (1), Yunlin (1), Nantow (2) & $3.5-4.8$ \\
Pear & Taichung (1), Chiayi (1) & 4.9 \\
Loquat & Yunlin (1), Taichung (1), Maioli (1), Taitung (1) & $4.5-5.0$ \\
Persimmon & Chiayi (1) & 4.6 \\
Carambola & Tainan (2) & $4.6-4.8$ \\
Wax apple & Chiayi (1) & 4.7 \\
Grape & Taichung (1) & $\mathrm{NT}^{\mathrm{y}}$ \\
Jellyfig & Chiayi (1), Taitung (1) & $-^{\mathrm{z}}$ \\
\hline
\end{tabular}

${ }^{\mathrm{x}} \mathrm{pH}$ of uninfected soils ranged from 3.8 to 8.0 .

y Not detected.

${ }^{\mathrm{z}}$ Jellyfig was attached to stone for growth, and the main root was not infected.

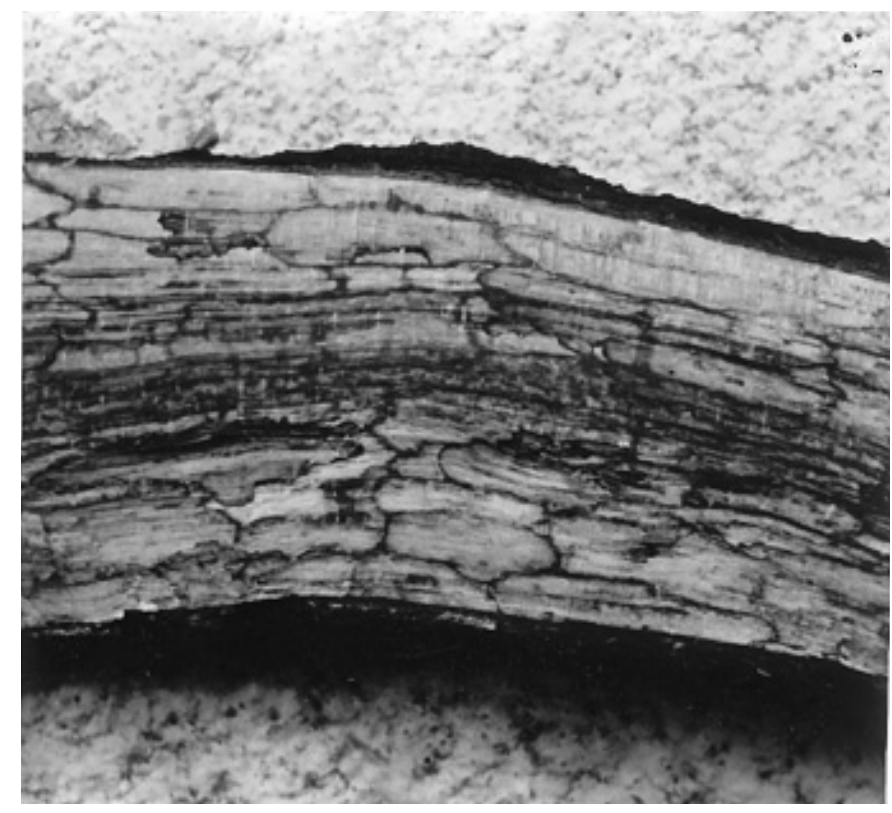

Fig. 1. Brown lines and networks on infected root tissue of a plumum tree. 
celial mats were observed in stem sections of dead trees up to $3 \mathrm{~m}$ high.

Pathogenicity tests. One year after inoculation, the percentages of seedlings killed by the isolates were $40 \%$ (litchi), 90\% (sugar-apple), $80 \%$ (plumum), $70 \%$ (pear), 100\% (loquat), 60\% (persimmon), $30 \%$ (carambola), 20\% (wax apple), $80 \%$ (grape), and 60\% (jellyfig) (combined mean of two tests). Tissues of the dead roots became soft with brown zone lines similar to the symptoms in the naturally infected trees. The same fungus was reisolated from all diseased roots of the artificially infected seedlings. All control seedlings remained healthy during the experiments.

Nine kinds of fruit seedlings ( 2 to 3 years old) and one isolate from each were used for cross-inoculation tests. Loquat was the most susceptible and wax apple was the most resistant to all of the nine tested isolates obtained from nine different hosts (Table 2). Some of the 2-year-old loquat seedlings wilted and died within 1 month after inoculation, 80 to $90 \%$ died after 6 months, and all died within 1 year. Sugar-apple, plumum, pear, and persimmon were also highly susceptible to all tested isolates, which killed at least $40 \%$ of the inoculated seedlings of these four fruit trees (Table 2). One hundred percent of the inoculated wax apple seedlings survived in some treatments, but with light discoloration in the inoculated tissues. Some of the tested isolates, such as those from carambola and wax apple, appeared to cause higher death rates on their original host plants than did other isolates.

Production of fruiting bodies. During rainy periods, hard, resupinate fruiting bodies were found at the base of a litchi tree and a sugar-apple tree in Chiayi and Taitung, respectively. The fruiting bodies were whitish initially, and their centers turned yellowish and brown gradually. Eventually all of the fruiting bodies became dark gray or brownish gray. No basidiospores were found in the natural fruiting bodies.

Fruiting bodies were not formed on the inoculated stem and root sections of the litchi trees. However, all tested isolates produced hard and unevenly resupinate fruiting bodies, about 0.5 to $2.0 \mathrm{~cm}$ thick on sawdust medium after 3 to 4 months, similar to those produced in nature. The fruiting bodies were yellowish brown with a white margin initially, turning brown and then dark gray subsequently. Basidia and basidiospores were found in the tubes. Basidiospores were smooth, hyaline, and ovoid to broadly ellipsoid, averaging from $4.0 \times 3.8 \mu \mathrm{m}$ to $6.0 \times 4.8 \mu \mathrm{m}$ (Table 3 ). Contextual setal hyphae were reddish brown and 370 to $602 \mu \mathrm{m}$ long for different isolates (Table 3).

Identification of the pathogen. All tested isolates were whitish on PDA during the early stages of growth. Subsequently, the colonies turned brown with irregular dark brown zone lines or patches permeating the culture. Clamp connections were absent. Conidia were not found, but arthrospores and trichocysts similar to those of longan isolates previously described (1) were commonly present in the culture. The arthrospores were spherical to ovoid, and trichocysts were dark brown.

The fungus was identified as Phellinus noxius (Corner) G.H. Cunningham (=Fomes noxius Corner) of the Hymenochaetaceae, Aphyllophorales based on the key of Polyporaceae (4). It was identical to the fungus causing serious decline of longan trees in Taiwan, which was reported in 1992 (1).

Growth of fungi. All of the tested isolates showed similar growth response to temperature, with an optimum temperature near $30^{\circ} \mathrm{C}$, maximum temperature above $36^{\circ} \mathrm{C}$, and minimum temperatures of 10 to $12^{\circ} \mathrm{C}$. However, the growth rates of different isolates at the optimum growth tem- perature varied dramatically (Fig. 2). The linear growth rates, on average, were 3.4 $\mathrm{cm} /$ day for the fastest growing isolate (a loquat isolate) to $0.8 \mathrm{~cm} /$ day for a grape isolate. Every tested isolate grew very slowly in the first 3 to 4 days and reached the maximum growth rate after 5 to 6 days.

All tested isolates preferred acidic conditions. Mycelia of the tested isolates were able to grow in PD broth with original $\mathrm{pH}$ ranging from 3.5 to 7.0. No growth was observed at $\mathrm{pH}$ above 7.5. At the original $\mathrm{pH}$ values of 4.5 to 7.0 (0.5 intervals), the mean dry weights of mycelial mats of the tested litchi isolate produced in $100 \mathrm{ml}$ of PD broth at $30^{\circ} \mathrm{C}$ after 10 days were 0.151 , $0.147,0.164,0.153,0.148$, and $0.155 \mathrm{~g}$, respectively, showing no significant difference according to the least significant difference test (LSD) at $P=0.05$. Under the same conditions, the plumum isolate produced $0.149,0.147,0.153,0.162,0.157$, and $0.162 \mathrm{~g}$, respectively, not a significant difference either $(P=0.05)$. However, the dry weights of mycelial mats produced with original $\mathrm{pH}$ values of 3.5 and 4.0 were 0.1 and $0.113 \mathrm{~g}$ (the litchi isolate) and 0.1 and $0.122 \mathrm{~g}$ (the plumum isolate), respectively, which were significantly different from those produced with original $\mathrm{pH}$ values ranging from 4.5 to $7.0(P=0.05)$. After fungal growth, $\mathrm{pH}$ of the $\mathrm{PD}$ broth dropped from the original $\mathrm{pH}$ values of 3.5 and 7.0 down to 3.3 and 5.5, respectively. The $\mathrm{pH}$ values of the noninoculated PD broth remained constant or changed slightly.

Dissemination tests. The percent mortality of 3-month-old seedlings of sugarapple transferred to pots containing rhizo-

Table 3. Size of sexual organs of seven isolates of Phellinus noxius isolated from different fruit trees ${ }^{2}$

\begin{tabular}{lcc}
\hline Source and no. of isolate & Length of setal hyphae $(\boldsymbol{\mu m})$ & Basidiospores $(\boldsymbol{\mu m})$ \\
\hline Litchi (PNL2) & $300-640(464)$ & $3.0-7.0 \times 3.0-5.4(4.7 \times 3.9)$ \\
Sugar-apple (PNA3) & $250-610(439)$ & $3.6-8.0 \times 1.6-4.0(5.1 \times 2.6)$ \\
Plumum (PNP2) & $278-550(370)$ & $3.0-7.0 \times 2.2-5.0(4.5 \times 3.9)$ \\
Loquat (PNLo1) & $350-920(602)$ & $3.5-4.8 \times 3.0-4.5(4.0 \times 3.8)$ \\
Persimmon (PNPe1) & $360-800(516)$ & $3.0-6.0 \times 2.0-4.0(4.4 \times 4.0)$ \\
Carambola (PNS1) & $300-620(424)$ & $5.8-9.0 \times 3.8-6.0(6.0 \times 4.8)$ \\
Wax apple (PNW1) & $175-670(417)$ & $4.0-9.0 \times 3.0-7.0(5.5 \times 4.5)$ \\
\hline
\end{tabular}

${ }^{\mathrm{z}}$ Fruiting bodies were artificially produced by inoculation of sawdust medium with fungus for 1 month and placed on moist sands for 2 to 3 months.

Table 2. Cross inoculation of nine isolates of Phellinus noxius on seedlings of nine different fruit trees

\begin{tabular}{|c|c|c|c|c|c|c|c|c|c|}
\hline \multirow{2}{*}{$\begin{array}{l}\text { Source of } \\
\text { isolate from }\end{array}$} & \multicolumn{9}{|c|}{ Percentage of seedlings killed after 1 year } \\
\hline & Longan & Litchi & Sugar-apple & Plumum & Pear & Loquat & Persimmon & Carambola & Wax apple \\
\hline Longan & $60 \mathrm{a} \mathrm{AB}^{\mathrm{y}}$ & 60 a $\mathrm{AB}$ & 100 a A & 100 a A & 80 a $\mathrm{A}$ & 100 a A & $90 \mathrm{ab} A$ & $60 \mathrm{ab} \mathrm{AB}$ & $20 \mathrm{ab} B$ \\
\hline Litchi & $30 \mathrm{ab} C D$ & 50 a BD & 100 a A & 100 a $\mathrm{A}$ & 70 a $\mathrm{AB}$ & 100 a A & 100 a A & $20 \mathrm{~b} \mathrm{CD}$ & $0, \mathrm{D}^{\mathrm{z}} \mathrm{b} \mathrm{D}$ \\
\hline Sugar apple & $40 \mathrm{ab} C$ & 70 a $\mathrm{A}-\mathrm{C}$ & 100 a A & 80 a $\mathrm{AB}$ & 80 a $\mathrm{AB}$ & 100 a A & $90 \mathrm{ab} A$ & 60 a $\mathrm{AB}$ & $0, \mathrm{D} b \mathrm{D}$ \\
\hline Plumum & $20 \mathrm{~b} \mathrm{~B}$ & 70 a A-C & 100 a A & 100 a A & 100 a A & 100 a A & $60 \mathrm{ab} \mathrm{AB}$ & $20 \mathrm{~b} \mathrm{~B}$ & $20 \mathrm{ab} B$ \\
\hline Pear & $30 \mathrm{ab} B C$ & 30 a $\mathrm{BC}$ & 100 a A & 60 a $\mathrm{AB}$ & 80 a $\mathrm{AB}$ & 100 a A & $40 \mathrm{~b} \mathrm{BC}$ & $60 \mathrm{ab} \mathrm{AB}$ & $0, \mathrm{D}$ b C \\
\hline Loquat & 40 ab B & 30 a B & 100 a A & 80 a A & 80 a A & 100 a A & $80 \mathrm{ab} A$ & $20 \mathrm{~b} \mathrm{BC}$ & $0, \mathrm{D}$ b C \\
\hline Persimmon & 40 ab B-D & 30 a CD & 80 a A-C & 100 a A & 60 a A-D & 100 a A & $90 \mathrm{ab} \mathrm{AB}$ & $40 \mathrm{ab}$ B-D & $20 \mathrm{ab} D$ \\
\hline Carambola & $30 \mathrm{ab} D$ & 50 a C & 80 a B & 100 a A & $60 \mathrm{a} \mathrm{C}$ & 100 a A & 100 a A & 80 a B & $0, \mathrm{D} b \mathrm{E}$ \\
\hline Wax apple & 60 a BC & 70 a B & 100 a A & 100 a A & 60 a BC & 100 a A & $60 \mathrm{ab}$ BC & $40 \mathrm{ab} C$ & $40 \mathrm{a} \mathrm{C}$ \\
\hline
\end{tabular}

${ }^{y}$ Means $(n=2)$ in the same column followed by the same small letter or in the same row followed by the same capital letter are not significantly different according to the least significant difference test $(P=0.05)$.

${ }^{\mathrm{z}} \mathrm{D}$ : Inoculated seedlings were not killed, but inoculated portions turned brown in some plants. 
sphere soil taken from an infected longan orchard was $61 \%$ after 3 months and $72.2 \%$ after 6 months. The average stem length of the surviving seedlings was only $33.2 \%$ that of the controls. P. noxius was consistently isolated from the dead root tissues. All of the seedlings planted in healthy soil survived and no disease symptoms were observed.

When 6-month-old loquat seedlings were planted in the pots containing dead root tissues from plants artificially inoculated with $P$. noxius, one seedling wilted after 8 months, and $30 \%$ died after 1 year. The remainder of the surviving seedlings grew slowly and were weaker than those planted in the soil with healthy root tissues. All of the seedlings planted in the pots containing healthy plant roots survived, and no disease symptoms were observed. The average stem length of the survivors was about $70 \%$ of those of the healthy controls. P. noxius was isolated from the roots of both dead and diseased seedlings.

\section{DISCUSSION}

$P$. noxius is widely distributed in the tropical and subtropical regions $(2,4,10)$. It causes brown root rot of hundreds of woody species. A number of important agricultural crops, including oil palm, cocoa, rubber, and tea, are highly susceptible (10). In Taiwan, tea and coffee were documented as hosts of $P$. noxius in the 1950s (12). However, the causal fungus has never been isolated, and further studies of brown root rot were discontinued until the late 1980s. Longan was the first important crop proven to be attacked by $P$. noxius in Taiwan, where the fungus caused serious brown root rot and considerable economic loss (1). Later, several forest trees were reported to be infected with the same fungus (3). Wilt of some sugar-apple trees was also thought to be related to $P$. noxius in a preliminary study (7). The present study shows that decline of 10 important fruit crops in Taiwan was also caused by brown root rot caused by $P$. noxius. Brown root rot caused by $P$. noxius has not been previously reported on these 10 fruit tree species.

$P$. noxius and P. lamaensis (=Fomes lamaensis) are closely related species. Phellinus lamaensis was reported to be the cause of brown root rot of a number of

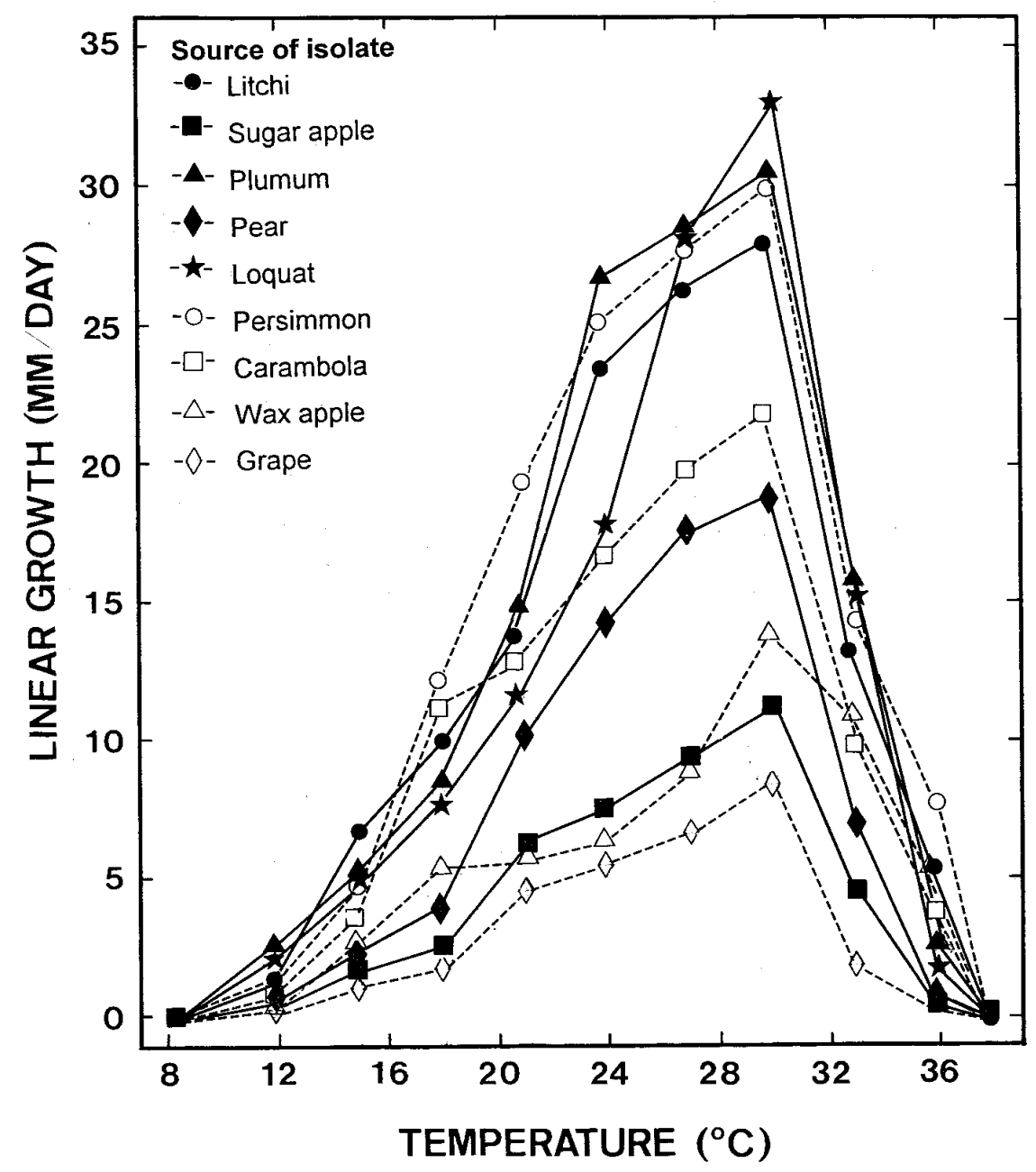

Fig. 2. Growth rate of eight isolates of Phellinus noxius from different fruit trees on potato dextrose agar. woody trees including longan in Taiwan (12). However, the causal relationship between P. lamaensis and brown root rot of longan and other crops has never been established. The main distinguishing characters in the two species are scanty hymenial setae and wide setal hyphae (up to 14 $\mu \mathrm{m}$ diameter) in $P$. noxius, and abundant hymenial setae and narrow setal hyphae (up to $7 \mu \mathrm{m}$ diameter only) in P. lamaensis $(4,10)$. All declining longan trees (1) and these 10 fruit crops surveyed during this study were associated with $P$. noxius. We did not isolate $P$. lamaensis from any declining fruit trees.

$P$. noxius preferred acidic conditions and did not grow at $\mathrm{pH}$ values higher than 7.5. This was consistent with the observation that all diseased soils infested with $P$. noxius had $\mathrm{pH}$ values equal to or lower than 5.0 (3.8 to 8.0 for healthy soils; Table 1). This also indicated that liming soil may be a useful means for management of brown root rot disease, although further study is needed. $P$. noxius preferred higher temperatures (Fig. 2), which explained the occurrence of most of the cases of declining fruit trees in the central and southern areas of Taiwan. Nicole et al. (9) reported that variability in virulence was found among isolates of $P$. noxius from West Africa. In our tests, some isolates appeared to cause higher mortality on their original host plants (Table 2). From the data obtained in this study, there appears to be no host specificity among the nine isolates from the different host plants. Variability of virulence of the nine tested isolates was noticed but was not significantly different among isolates $(P=0.05)$ in most crosscombinations. The variability in virulence and difference in growth rates among the tested isolates also did not show significant correlation $(P=0.05)$.

Although longan trees were infected more frequently than other species in the field in Taiwan (1), longan seedlings showed more resistance to $P$. noxius than many other fruit seedlings in the inoculation test. Most of the tested fruit seedlings were highly or moderately susceptible to the pathogen; only the seedlings of wax apple were highly resistant. Natural infection of wax apple in a monoculture orchard was never observed. Only a single wax apple tree was found to be killed in a multicropping field, probably from higher inoculum density related to the proximity of susceptible hosts.

Airborne basidiospores of $P$. noxius have been reported to be able to cause butt rot of freshly exposed tree stumps (10). However, fruiting bodies of the fungus rarely formed on the trunks or basal stems of the diseased trees in our survey. Also, all diseased fruit trees attacked by $P$. noxius exhibited only root infection. Stem infection was not observed. Since brown root rot could be induced by replanting sugar-apple seedlings in the diseased soil, and healthy roots of 
loquat seedlings became infected following contact with diseased or dead roots, we believe that most cases of brown root rot of fruit trees occurring in Taiwan were due to root infection caused by contact with mycelia of $P$. noxius in soil.

\section{ACKNOWLEDGMENTS}

We thank the Agricultural Council (ROC) for part of the financial support.

\section{LITERATURE CITED}

1. Ann, P. J., and Ko, W. H. 1992. Decline of longan trees: Association with brown root rot caused by Phellinus noxius. Plant Pathol. Bull. 1:19-25.

2. Browne, F. G. 1968. Pests and Diseases of Forest Plantation Trees. Oxford University
Press, London.

3. Chang, T. T. 1992. Decline of some forest trees associated with brown root rot caused by Phellinus noxius. Plant Pathol. Bull. 1:90-95.

4. Cunningham, G. H. 1965. Polyporaceae in New Zealand. N.Z. Dep. Sci. Ind. Res. Bull. 164:1-304.

5. Hodges, C. S., and Tenorio, J. A. 1984. Root disease of Delonix regia and associated tree species in the Mariana Islands. Plant Dis. 68:334-336.

6. Ko, W. H., Tomita, J., and Short, R. L. 1986. Two natural hosts of Kretzschmaria clavus in Hawaiian forests. Plant Pathol. 35:254-255.

7. Lee, H. L., and Huang, T. C. 1992. Preliminary studies on wilt disease of custard apple. (Abstr. in Chinese.) Plant Prot. Bull. 33:433.

8. Miller, M. W., and Jong, S. C. 1987. Commercial cultivation of shiitake in sawdust filled plastic bags. Pages 421-426 in: Cultivating Edible Fungi. P. J. Wuest, D. J Royse, and R. B. Beelman, eds. Elsevier, Amsterdam.

9. Nicole, M., Nandris, D., Geiger, J. P., Rio, B. 1985. Variability among African populations of Rigidoporus lignosus and Phellinus noxius. Eur. J. For. Pathol. 15:293-300.

10. Pegler, D. N., and Waterston, J. M. 1968. Phellinus noxius. C.M.I. Descriptions of Pathogenic Fungi and Bacteria. No. 195.

11. Ryan, F. J., Beadle, G. W., and Tatum, E. L. 1943. The tube method of measuring the growth rate of Neurospora. Am. J. Bot. 30:784-799.

12. Tsai, Y. P. 1991. List of Plant Diseases in Taiwan. 3rd ed. Plant Prot. Soc. China \& Plant Phytopathol. Soc. China. Taichung, Taiwan. 